\title{
The phenotypic relationship between residual intake and gain and others feed efficiency traits in
} Nellore cattle

Darcilene Maria de Figueiredo $^{\mathrm{a}, *}$, Maria Eugênia Zerlotti Mercadante ${ }^{\mathrm{b}}$, Aldrin Vieira Pires ${ }^{\mathrm{a}}$, Renata Helena Branco $^{\mathrm{b}}$, Enilson Geraldo Ribeiro ${ }^{\mathrm{c}}$, Gabriel Machado Dallago ${ }^{\mathrm{a}}$, Marianne Schorer ${ }^{\mathrm{a}}$, Pedro Ribeiro Rocha ${ }^{\mathrm{d}}$

${ }^{a}$ Departamento de Zootecnia, Universidade Federal dos Vales do Jequitinhonha e Mucuri - JK Campus, Diamantina, MG 39.100-000, Brazil

b Instituto de Zootecnia, Centro APTA Bovinos de Corte, Sertãozinho, SP 14.160-900, Brazil

${ }^{\mathrm{c}}$ Instituto de Zootecnia, Centro APTA Bovinos de Leite, Nova Odessa, SP 13.460-000, Brazil

d Instituto Federal de Ciência e Tecnologia de Mato Grosso - Juína Campus, Juína, MT 78.320-000, Brazil *Corresponding author: Departamento de Zootecnia, Universidade Federal dos Vales do Jequitinhonha e Mucuri - JK Campus, Rodovia MGT 367 - Km 583, 5000, Diamantina - MG, 39.100-000, Brazil. Tel.: +55383532 - 8510. Cel.: +55 38 98845-5770. E-mail: darcilenefigueiredo@ gmail.com (D.M. Figueiredo)

Abstract: This study aimed to compare feed efficiency measures of Nellore beef cattle on different residual intake and gain (RIG) classes. We used data from 610 animals weighing on average $236.33 \mathrm{~kg}$ and average of 283 days of age from feedlot performance tests carried out between 2005 and 2012. Animals were grouped based on RIG into three different classes: high RIG (> mean +0.5 standard deviation (SD), most efficient; $\mathrm{n}=193$ ), medium RIG (mean $\pm 0.5 \mathrm{SD} ; \mathrm{n}=235)$, and low RIG (< mean $-0.5 \mathrm{SD}$, least efficient; $\mathrm{n}=182$ ). Residual feed intake (RFI), residual gain (RG), feed conversion ratio (FCR), feed efficiency (FE), relative growth rate (RGR), and Kleiber ratio (KR) of animals in each RIG class were compared by Tukey test at $1 \%$ of probability. Phenotypic correlations between variables were evaluated as well. Animals on high RIG class showed lower dry matter intake $(\mathrm{P}<0.01)$ and higher average daily gain $(\mathrm{P}<0.01)$ than low RIG animals. Consequently, high RIG animals had lower FCR $(\mathrm{P}<0.01)$ and higher FE $(\mathrm{P}<0.01)$ than those animals in low RIG class. The most efficient animals based on RIG were also the most efficient animals based on RG and RFI. RIG was negatively correlated to dry matter intake $(\mathrm{P}<0.01)$ and FCR $(\mathrm{P}$ $<0.01$ ), and a positive correlation was found between RIG and FE ( $\mathrm{P}<0.01)$. Therefore, RIG appears to be a good parameter to select animals with reduced dry matter intake and high productive performance.

Keywords: animal performance, beef production, feed efficiency, genetic improvement. 


\section{Introduction}

Raising animals that use diet nutrients more efficiently could be a means of reducing production costs (Almeida 2005) in addition to maximize the usage of forage from pasture. Tropical beef cattle are mainly raising on pasture systems, which are characterized by irregular roughage production due to differences in water precipitation throughout the year (Silva et al. 2008). Therefore, breeding genetically high feedefficiency animals could be an important objective to maximize pasture usage and reduce production cost (Arthurand Herd 2008), but maintaining reproduction performance and meat quality.

Genetic improvement of beef cattle was initially based on feed conversion ratio (FCR) or on feed efficiency (FE). Animals selected based on these metrics allowed for identifying those with more efficient growth rate, but it did not take into account reduction in dry matter intake. Consequently, animals would be of big size at mature age, which would increase their energy requirement for maintenance (Arthur et al. 2001a). This situation might present major drawbacks, such as compromising female's reproductive efficiency in limiting nutritional conditions such as those commonly observed under pasture-fed system.

The residual feed intake (RFI) proposed by Koch et al. (1963) measures feed efficiency independently of growth rate and weight at mature age. It is defined as the difference between the observed feed intake and the expected feed intake, which in turn is estimated based on animals' metabolic body weight $\left(\mathrm{BW}^{0.75}\right)$ and expected average daily gain. Therefore, RFI measures changes in energy of maintenance requirements independent of body size and production level.

Even though RFI might be a good measure of feed efficiency, it is not related to the average daily gain (Branco et al. 2011). Residual gain (RG) was then proposed by Koch et al. (1963) adjusting the gain relative to feed intake. Altogether, RFI and RG are used to calculate the residual intake and gain (RIG), which aims to select animals that are more efficient. In other words, RIG selects animals with low feed intake and fast development, overcoming a possible rejection by the producers for the RFI because it is not related to the average daily gain.

Therefore, this study aimed at comparing results of Nellore beef cattle of different RIG classes evaluated through feedlot performance tests.

\section{Materials and Methods}


Data used in the present study were extracted from a pre-existing dataset which was obtained under commercial conditions. Therefore, no approval was necessary from the Ethics Committee on the Use of Animals from the Federal University of the Jequitinhonha and Mucuri Valleys in order to conduct this study.

The study was carried out at the Centro APTA Bovinos de Corte located at $21^{\circ} 10^{\prime}$ South latitude and $48^{\circ}$ 57' West longitude. According to the Köppen, the climate of the region is classified as Aw - tropical humid climate with dry winter (Rolim et al. 2007).

The genetic improvement program of Nellore beef cattle of Centro APTA Bovinos de Corte started in 1978. The original herd was split in three lines of selection: Selection Nellore (SNe), Traditional Nellore (TNe), and Control Nellore (CNe). Animal selection in all of the three groups was done within the contemporary group (herd vs. year of birth). Animals on SNe and TNe were selected for greater post-weaning weight and animals in the $\mathrm{CNe}$ line was selected for average post-weaning weight (Coutinho et al. 2015, Mercadante et al. 2003). Males were selected for yearling weight adjusted to 378 days of age (P378) obtained after feeding performance test for 168 days, and females were selected for post-weaning weight adjusted to 550 days of age (P550) obtained on pasture.

Records from males $(n=326)$ and females $(n=352)$ Nellore beef cattle from the three lines of selection ( $\mathrm{SNe}, \mathrm{TNe}$, and $\mathrm{CNe}$ ) were used. The progeny born between 2004 and 2011 participated in feeding performance tests carried out between the months of July and December of the years between 2005 and 2012. In order to analyze the data, all animals were placed into groups (G1 to G12) according to the year of the performance test, year of birth, selection line, and sex (Table 1).

Dry matter intake (DMI) and average daily gain (ADG) were collected in performance tests after weaning. Prior to the feeding performance test, at least 56 days of adaptation to the diet and experimental conditions were allowed to the animals. They were placed in individual pens equipped with the GrowSafe $₫$ System (GrowSafe Systems Ltd., Airdrie, Alberta, Canada) for $82 \pm 17$ days. They were fed twice a day, at 8 a.m. and 3 p.m., with ad libitum access to the diet and clean fresh water. Diets offered to the animals changed over the years, but it was yearly equivalent on crude protein $(12.9 \% \pm 1.4)$ and total digestible nutrients $(62.6 \% \pm 3.4)$ (Table 2). 
Average dry matter intake (DMI) was calculated as the difference between offered feed and leftovers throughout the tests. Leftovers were adjusted three times a week to represent $5 \%$ to $10 \%$ of the total amount offered to ensure ad libitum condition to all animals.

Animals were weighed for the first time after 16 hours fasting. After the first weighing, animals from different groups were weighed following different time interval during the tests. Groups G1 and G2 were weighed every 14 days after fasting for 12 hours. Groups G3, G4, G6, G8, and G9 were weighed every 28 days after 12 hours of fasting. Groups G5 and G7 were weighed weekly on three consecutive days with no fasting. Animals from group G10 was weighed weekly on two consecutive days with no fasting. Group G11 was weighed once a week with no fasting. Lastly, group G12 was weighed on two consecutive days every 15 days with no fasting.

Average daily gain (ADG) was calculated by linear regression of weights measured throughout the days of test (DOT) as follows:

$$
\mathrm{y}_{\mathrm{i}}=\alpha+\beta^{*} \mathrm{DOT}_{\mathrm{i}}+\varepsilon_{i}
$$

where yi is the animal's body weight in the $\mathrm{i}^{\text {th }}$ observation; $\alpha$ is the intercept, which indicate the initial weight; $\beta$ is the linear regression coefficient representing ADG; DOTi is the days on test in the $i^{\text {th }}$ observation, and $\varepsilon_{\mathrm{i}}$ is the random error associated with each observation.

Performance and feed efficiency traits were evaluated based on initial body weight (BWi), final body weight (BWf), and average body weight (average between BWi and BWf). The mid-test metabolic body weight $\left(\mathrm{BW}^{0.75}\right)$ was calculated as presented by Nkrumah et al. (2004):

$$
\mathrm{BW}^{0.75}=\left[\alpha+\beta^{*}\left(\frac{\mathrm{DOT}}{2}\right)\right]^{0.75}
$$

where $\mathrm{BW}^{0.75}$ is the mid-test metabolic body weight; $\alpha$ is the intercept, which indicates the initial body weight; $\beta$ is the linear regression coefficient representing $\mathrm{ADG}$, and DOT is the total length of the test (days).

Feed conversion ratio (FCR) was obtained as the ratio between DMI and ADG. Feed efficiency (FE), on the other hand, was calculated as the ratio between ADG and DMI.

Relative growth rate (RGR) was calculated using the logarithm of BWi and BWf over DOT as follows: 
Kleiber ratio (KR), proposed by Kleiber (1936), was calculated as:

$$
\mathrm{KR}=\frac{\mathrm{ADG}}{\mathrm{BW}^{0.75}}
$$

where $\mathrm{KR}$ is the Kleiber ratio; $\mathrm{ADG}$ is the average daily gain during the tests, and $\mathrm{BW}^{0.75}$ is the mid-test metabolic body weight.

Residual feed intake (RFI) was calculated according to Koch et al. (1963) as the difference between observed DMI during the test period and the expected DMI, estimated using the follow regression model:

$$
\mathrm{DMI}=\beta_{0}+\beta_{1} \mathrm{ADG}+\beta_{2} \mathrm{BW}^{0.75}+\varepsilon
$$

where DMI is the expected dry matter intake; $\beta_{0}$ is the intercept; $\beta_{1}$ is the partial regression coefficient of

$\mathrm{DMI}$ on $\mathrm{ADG} ; \beta_{2}$ is the partial regression coefficient of DMI on $\mathrm{BW}^{0.75}$; and $\varepsilon$ is the RFI.

Residual gain (RG) was calculated using the following linear regression model (Crowley et al. 2010):

$$
\mathrm{ADG}=\beta_{0}+\beta_{1} \mathrm{ADG}+\beta_{2} \mathrm{BW}^{0.75}+\varepsilon
$$

where ADG is the average daily gain; $\beta_{0}$ is the intercept; $\beta_{1}$ and $\beta_{2}$ are the partial regression coefficients of $\mathrm{ADG}$ on $\mathrm{DMI}$ and $\mathrm{BW}^{0.75}$, respectively; and $\varepsilon$ is the $\mathrm{RG}$.

Residual intake and gain (RIG) was calculated using the equation proposed by Berry and Crowley (2012) as follows:

$$
\mathrm{RIG}=\frac{\mathrm{RG}}{\sigma_{\mathrm{RG}}}-\frac{\mathrm{RFI}}{\sigma_{\mathrm{RFI}}}
$$

where $\sigma_{\mathrm{RG}}$ is the standard deviation of the average $\mathrm{RG}$ from the contemporary group and $\sigma_{\mathrm{RFI}}$ is the standard deviation of the average RFI from the contemporary group.

Residual intake and gain (RIG) was used to group the animals into three different classes: high RIG (> mean +0.5 standard deviation $(\mathrm{SD})$, most efficient animals; $\mathrm{n}=193)$, medium RIG $($ mean $\pm 0.5 \mathrm{SD} ; \mathrm{n}=$ 235), and low RIG (< mean - 0.5 SD, least efficient animals; $\mathrm{n}=182$ ). Animals with more than one record outside the interval of \pm 3.5 standard deviations from the mean of the contemporary group $(n=68)$ were eliminated from the database. 
A completely randomized design was used. Each class of RIG was considered the treatment and the number of animals in each of the classes were considered repetitions. Sex was considered a random effect in establishing contemporary groups. The fixed effect of RIG classes, the random effect of contemporary groups, and the covariate age were included in the model using PROC MIXED of SAS (1999). Means were adjusted by the least squares method using LSMEANS of SAS (1999). RIG classes were compared by Tukey test at $1 \%$ of probability. Correlations between variables were calculated using PROC CORR of SAS (1999).

\section{Results}

Initial body weight $(\mathrm{BWi})$, final body weight $(\mathrm{BWf})$, and metabolic body weight $\left(\mathrm{BW}^{0.75}\right)$ were not statistically different $(\mathrm{P}>0.01)$ between high, medium, and low residual intake and gain (RIG) classes (Table 3), which indicated homogeneity of the herds evaluated.

Dry matter intake $(\mathrm{DMI})$ was statistically different $(\mathrm{P}<0.01)$ between RIG classes. On average, animals on high and medium RIG classes consumed $0.600 \mathrm{~kg}$ lesser than those animals on low RIG class (Table 3). Average daily gain (ADG) was different between RIG classes as well. Animals from high RIG class showed higher ADG than animals from low RIG class $(\mathrm{P}<0.01)$, meaning that higher RIG animals are able to gain more weight with reduced DMI than lower RIG animals (Table 3).

RIG values of $-0.481,0.003$, and 0.451 respectively, for low, medium, and high RIG classes were statistically different $(\mathrm{P}<0.01)$ (Table 4). RFI values were statistically different $(\mathrm{P}<0.01)$ between RIG classes and they were in accordance with the results found for RIG. The least efficient animals based on RFI (positive value) were also the least efficient animals based on RIG classification (negative value). The opposite was also true. The most efficient animals based on RFI (negative value) were the most efficient animals based on RIG (positive value) as well. Thus, animal selection based on RFI would simultaneously select efficient animals regarding their RIG (Table 4).

RG statistically differed $(\mathrm{P}<0.01)$ between RIG classes (Table 4). The most efficient animals based on RIG were also the most efficient animals based on RG and the opposite was also true. Since RG is related to ADG, most efficient RG animals gained more weight than those inefficient RG animals. It confirmed that selection based on RIG also selects animals that are more efficient at converting their feeding, reducing the time required by the animals to reach slaughter weight. 
Kleiber ratio (KR) represents the $\mathrm{ADG}$ proportional to each $\mathrm{kg}$ of $\mathrm{BW}^{0.75}$. KR values were not different (P > 0.01) between RIG classes in our study (Table 4). According to Bergh et al. (1992) and Arthur et al. (2001b) high RIG values are desired.

According to Fitzhugh Jr and Taylor (1971), high values of relative growth rate (RGR) are desired since it indicates potential growth at adult age. The RGR values of $0.151,0.158$, and 0.154 respectively observed for low, medium, and high RIG classes were not statistically different $(\mathrm{P}>0.01)$ in our study.

FCR and FE, two indexes commonly used to measure animals' efficiency on transforming their feed into products such as meat, statistically differed between RIG classes $(\mathrm{P}<0.01)$. It is desired values of FCR as low as possible while the opposite is aimed for FE. Feed conversion ratio of animals from high RIG class was $14.3 \%$ lower $(7.01 \mathrm{~kg}$ of DMI/ $\mathrm{kg}$ of body weight gain) than animals from low RIG class $(8.18 \mathrm{~kg}$ of DMI/kg of body weight gain) (Table 4). The results observed for FE in our study were similar to FCR, though the interpretation of the result is the opposite as FCR since high values are aimed. We found higher $(\mathrm{P}<0.01) \mathrm{FE}$ for animals in high RIG class $(0.15 \mathrm{~kg}$ ADG/Kg DMI) compared to animals on low RIG class (0.13 kg ADG/Kg DMI) (Table 4).

Table 5 shows the results of phenotypic correlations between variables evaluated in our study. No significant correlation $(\mathrm{P}>0.01$ ) was observed between feed efficiency measures (RFI, RG, and RIG) and $\mathrm{BWi}, \mathrm{BWf}$, and $\mathrm{BW}^{0.75}$. ADG was not significantly correlated $(\mathrm{P}>0.01)$ to RFI in our study as well. On the other hand, DMI $(\mathrm{kg} /$ day and \% $\mathrm{BW})$ was positively correlated $(\mathrm{P}<0.01)$ to RFI $(0.31$ and 0.50 , respectively). Phenotypic correlation was negative $(\mathrm{P}<0.01)$ between RFI and RG $(-0.56)$, but positive $(\mathrm{P}$ $<0.01)$ between RFI and RIG (-0.98). RG was not linearly correlated (P > 0.01) with DMI (kg/day and \% BW), but was moderately correlated (0.42) with ADG and RIG (0.70). A negative phenotypic correlation of -0.27 was found between RIG and DMI. Lastly, a negative phenotypic correlation coefficient of -0.31 $(\mathrm{P}<0.01)$ was found between FCR and RIG.

\section{Discussion}

Our findings suggests that high RIG animals are more efficient than low RIG animals. A similar result has been reported by Berry and Crowley (2012). They conducted a study to evaluate daily gain and dry matter intake. Based on RIG values, they reported reduction on the amount of days required to reach $300 \mathrm{~kg}$ of BW (4 days on average). The same authors also observed a reduction on DMI of approximately 
$0.600 \mathrm{~kg} /$ animal $/$ day. These findings were similar to the ones found in our study and even though the reduction in feed intake by each animal was relatively small, the same result scaled to a larger number of animals would represent a much more significant reduction in feed consumption, without, however, compromising animal performance. In addition, it would be possible to increase beef production without increasing the amount of grazing land (Basarab et al. 2003, Nkrumah et al. 2006) and reduce methane production by 5 to $25 \%$ (Hegarty et al. 2007, Lassey et al. 2002, Nkrumah et al. 2006).

RIG and RFI could be used to select animals with reduced feed intake. Similar to our results, Berry and Crowley (2012) reported that the most efficient animals were the same based on both parameters. RFI is calculated as the difference between observed and predicted DMI based on $\mathrm{BW}^{0.75}$ and $\mathrm{ADG}$. As a selection tool, it would select animals that require less feed intake to perform well, but it does not account for growth rate and animal size. In their study, Berry and Crowley (2012) reported differences between initial and final body weight within groups of animals evaluated. Heterogeneity of the herd was hypothesized to be the reason for this result, but they did not find differences regarding average metabolic body weight. Arthur and Herd (2008) suggested that negative RFI values indicate changes on protein and lipid metabolism, such as change on body composition and protease activity. These metabolic changes would affect meat quality by reducing carcass fat content, which consequently improves meat succulence. Studying high and low RFI Angus-Hereford steers, Sainz et al. (2006) found no difference between both groups for hot carcass weight, backfat, longissimus muscle area, carcass fat, and marbling. Therefore, animal selection based on RFI is followed by carcass traits and meat quality.

Animals more efficient at transforming their feed into desired products according to FCR and FE are also the ones with higher RIG. FCR and FE are frequently used to evaluate cattle feed efficiency, but using them as a selection tool is limited due to their correlation with body weight and weight gain. It could compromise the productive efficiency of pasture based systems due to increase in adult size of breeding animals which in turn would increase their maintenance energy requirements (Magnani 2011).

Correlation analysis is an important tool on genetic improvement programs. It makes possible to select even characteristics of complex inheritance if they are correlated to another one easily identifiable. Therefore, it is important to be aware of possible associations among traits, resulting in improved selection efficiency regarding targeted features. 
216 No phenotypic correlation between feed efficiency measures (RFI, RG, and RIG) and BWi, BWf, and

$217 \mathrm{BW}^{0.75}$ confirmed that these traits are independent of growth and body size. It is then possible to select 218 animals independently of their adult requirement for maintenance energy (Grion 2012). Crowley et al. 219 (2011), studying genetic covariances between feed efficiency measures from 2605 purebred bulls 220 (Aberdeen, Angus, Hereford, Simmental, Limousin, and Charolais breed) and crossbred cows' reproductive and productive performance, found that these measures did not impair dams' performance. Lancaster et al. (2009) evaluated feed efficiency and phenotypic correlations using data from 468 Brangus heifers, and concluded that RFI would be useful in selection programs because it is less correlated to the growth rate as FCR. However, these are phenotypic correlation results and they aid in identifying animals that are more efficient, but only genetic correlations would show whether these traits would change across generations.

Supposing the phenotypic correlation between RG and ADG found in our study are also true for genetic correlation, selection based on RG would increase ADG (Robinsonand Oddy 2004). Phenotypic correlations similar to the ones found in our study has been previously reported. For instance, Grion et al. (2014) found phenotypic correlation of 0.59 between DMI (kg/day) and RFI. Crowley et al. (2010) reported phenotypical correlation of -0.40 between RFI and RG. Berry and Crowley (2012) found a strong negative correlation of -0.85 between RFI and RIG. Crowley et al. (2010) reported correlation of 0.70 between RG and ADG while Grion (2012) found that RG had phenotypic correlation of 0.69 with ADG. In agreement to our findings, these results indicate a linear relationship between these parameters, and even though they are phenotypic correlations, RG could be used to identify animals that are more efficient.

RIG appears to be the best parameters to use in order to select animals with decreased DMI but at the same time high productive performance. Grion et al. (2014) have reported high positive genetic correlations between DMI and BW as well as between DMI and ADG. It indicates a synergistic effect among them, making it hard to identify some trait that when selected would be beneficial for both of these characteristics of interest. We found a negative phenotypic correlation of -0.27 between RIG and DMI (Table 5). Similarly, previous studies have also reported negative phenotypic correlation ranging from -0.53 to -0.34 (Berryand Crowley 2012, Grion 2012). In addition, no correlation ( $\mathrm{P}>0.01)$ was found between RIG and ADG as well as RIG and BW in our study. Altogether, these results suggest that RIG would be the only trait capable of identifying animals showing reduced requirement on feed intake, but with a high productive performance at the same time. 
245 Similar to our results, Berry and Crowley (2012) also reported a negative correlation coefficient (-0.66)

246 between FCR and RIG, suggesting better FCR on high RIG animals compared to low RIG animals. Feed

247 efficiency was positively correlated to RIG and RG, but negatively correlated to RFI in our study. These

248 results suggests that animals selected based on these traits would show better FE compared to animals

249 selected based on ADG.

250 As a conclusion, our results suggest that high RIG animals perform better than low RIG. In addition, 251 phenotypic correlations indicate that RIG is a good parameter to select animals with reduced feed intake, but at the same time high productive performance. We, therefore, suggest its usage as a metric of 253 performance to be used on animal selection. Future studies could focus on evaluating possible associations between RIG and biometric parameters, since they are ease to be measured under practical conditions and could be an additional tool to improve animal breeding programs.

\section{Acknowledgements}

This work was financially supported by the Fundação de Amparo à Pesquisa do Estado de São Paulo (FAPESP), and a scholarship was granted to Pedro R. Rocha and Gabriel M. Dallago by the Coordenação de Aperfeiçoamento de Pessoal de Nível Superior (CAPES).

\section{Statement of Animal Rights}

261

All applicable international, national, and/or institutional guidelines for the care and use of animals were followed.

\section{Conflict of interest Statement}

The authors have no conflict of interest to declare.

\section{References}

Almeida, R., 2005. Consumo e eficiência alimentar de bovinos em crescimento (Thesis, Escola Superior de Agricultura Luiz de Queiroz, Universidade de São Paulo). 
Arthur, P.F., Archer, J.A., Johnston, D.J., Herd, R.M., Richardson, E.C. and Parnell, P.F. 2001a. Genetic and phenotypic variance and covariance components for feed intake, feed efficiency, and other postweaning traits in Angus cattle. Journal of Animal Science, 79(11), 2805-2811. doi: 10.2527/2001.79112805x

Arthur, P.F., Renand, G. and Krauss, D. 2001b. Genetic and phenotypic relationships among different measures of growth and feed efficiency in young Charolais bulls. Livestock Production Science, 68(2), 131-139. doi: 10.1016/S0301-6226(00)00243-8

Basarab, J.A., Price, M.A., Aalhus, J.L., Okine, E.K., Snelling, W.M. and Lyle, K.L. 2003. Residual feed intake and body composition in young growing cattle. Canadian Journal of Animal Science, 83(2), 189204. doi: $10.4141 / \mathrm{A} 02-065$

Bergh, L., Scholtz, M.M. and Erasmus, G.J., 1992. Identification and assessment of the best animal: The Kleiber ratio (growth / metabolic mass) as a selection criterion for beef cattle. Proceedings of the Australian Association of Animal Breeding Genetic, 1992, 338-340.

Berry, D.P. and Crowley, J.J. 2012. Residual intake and body weight gain: A new measure of efficiency in growing cattle. Journal of Animal Science, 90(1), 109-115. doi: 10.2527/jas.2011-4245

Branco, R.H., Magnani, E., Grion, A.L., Mercadante, M.E.Z., Bonilha, S.F.M. and Ribeiro, E., 2011. Consumo e ganho residual em bovinos Nelore classificados quanto ao consumo alimentar residual. Proceedings of the Reunião Anual da Sociedade Brasileira de Zootecnia, Brasília, Brazil, 2011, (Sociedade Brasileira de Zootecnia).

Coutinho, C.C., Mercadante, M.E.Z., Jorge, A.M., Paz, C.C.P., Faro, L.E. and Monteiro, F.M. 2015. Growth curves of carcass traits obtained by ultrasonography in three lines of Nellore cattle selected for body weight. Genetics and Molecular Research, 14(4), 14076-14087. doi: 10.4238/2015.October.29.27

Crowley, J.J., Evans, R.D., Mc Hugh, N., Kenny, D.A., McGee, M., Crews, D.H. and Berry, D.P. 2011. Genetic relationships between feed efficiency in growing males and beef cow performance. Journal of Animal Science, 89(11), 3372-3381. doi: 10.2527/jas.2011-3835 
Crowley, J.J., McGee, M., Kenny, D.A., Crews, D.H., Evans, R.D. and Berry, D.P. 2010. Phenotypic and genetic parameters for different measures of feed efficiency in different breeds of Irish performance-tested beef bulls. Journal of Animal Science, 88(3), 885-894. doi: 10.2527/jas.2009-1852

Fitzhugh Jr, H.A. and Taylor, C.S. 1971. Genetic analysis of degree of maturity. Journal of Animal Science, 33(4), 717-725. doi: 10.2527/jas1971.334717x

Grion, A.L., 2012. Parâmetros genéticos de medidas indicadoras de eficiência alimentar de bovinos de corte (Dissertation, Instituto de Zootecnia - IZ).

Grion, A.L., Mercadante, M.E.Z., Cyrillo, J.N.S.G., Bonilha, S.F.M., Magnani, E. and Branco, R.H. 2014. Selection for feed efficiency traits and correlated genetic responses in feed intake and weight gain of Nellore cattle1. Journal of Animal Science, 92(3), 955-965. doi: 10.2527/jas.2013-6682

Hegarty, R.S., Goopy, J.P., Herd, R.M. and McCorkell, B. 2007. Cattle selected for lower residual feed intake have reduced daily methane production. Journal of Animal Science, 85(6), 1479-1486. doi: $10.2527 /$ jas.2006-236

Kleiber, M. 1936. Problems involved in breeding for efficiency of food utilization. Proceedings of the American Society of Animal Nutrition, 1936b(1), 247-258. doi: 10.2527/jas1936.1936b1247x

Koch, R.M., Swiger, L.A., Chambers, D. and Gregory, K.E. 1963. Efficiency of Feed Use in Beef Cattle. Journal of Animal Science, 22(2), 486-494. doi: 10.2527/jas1963.222486x

Lancaster, P.A., Carstens, G.E., Crews, D.H., Welsh, T.H., Forbes, T.D.A., Forrest, D.W., Tedeschi, L.O., Randel, R.D. and Rouquette, F.M. 2009. Phenotypic and genetic relationships of residual feed intake with performance and ultrasound carcass traits in Brangus heifers1. Journal of Animal Science, 87(12), 3887 3896. doi: $10.2527 /$ jas.2009-2041

Lassey, K.R., Pinares-Patiño, C.S. and Ulyatt, M.J., 2002. Methane emission by grazing livestock: some findings on emission determinants. In: J.v. Ham et al. (eds), Proceedings of the Non-CO2 greenhouse gases: scientific understanding, control options and policy aspects, Rotterdam Netherlands, 2002, (Millpress), 95100. 
Magnani, E., 2011. Caracterização do consumo alimentar residual e relações com desempenho e metabolismo de fêmeas nelore (Dissertation, Instituto de Zootecnia - IZ).

Mercadante, M.E.Z., Packer, I.U., Razook, A.G., Cyrillo, J.N.S.G. and Figueiredo, L.A. 2003. Direct and correlated responses to selection for yearling weight onreproductive performance of Nelore cows1. Journal of Animal Science, 81(2), 376-384. doi: 10.2527/2003.812376x

Nkrumah, J.D., Basarab, J.A., Price, M.A., Okine, E.K., Ammoura, A., Guercio, S., Hansen, C., Li, C., Benkel, B., Murdoch, B. and Moore, S.S. 2004. Different measures of energetic efficiency and their phenotypic relationships with growth, feed intake, and ultrasound and carcass merit in hybrid cattle1. Journal of Animal Science, 82(8), 2451-2459. doi: 10.2527/2004.8282451x

Nkrumah, J.D., Okine, E.K., Mathison, G.W., Schmid, K., Li, C., Basarab, J.A., Price, M.A., Wang, Z. and Moore, S.S. 2006. Relationships of feedlot feed efficiency, performance, and feeding behavior with metabolic rate, methane production, and energy partitioning in beef cattle1. Journal of Animal Science, 84(1), 145-153. doi: $10.2527 / 2006.841145 x$

Robinson, D.L. and Oddy, V.H. 2004. Genetic parameters for feed efficiency, fatness, muscle area and feeding behaviour of feedlot finished beef cattle. Livestock Production Science, 90(2), 255-270. doi: 10.1016/j.livprodsci.2004.06.011

Rolim, G.d.S., Camargo, M.B.P.d., Lania, D.G. and Moraes, J.F.L.d. 2007. Classificação climática de Köppen e de Thornthwaite e sua aplicabilidade na determinação de zonas agroclimáticas para o estado de são Paulo. Bragantia, 66(4), 711-720. doi: 10.1590/S0006-87052007000400022

Sainz, R.D., Cruz, G.D., Monteiro, R.B., Rodriguez, J.A., Monteiro, D.B., Guidi, V. and Anaruma, R.J., 2006. Carcass composition and visceral organs are similar at harvest in low- and high-residual feed intake groups of Angus-Hereford steers. Proceedings of the Proceedings, Western Section, of the American Society of Animal Science, 2006, 401-403.

SAS 1999. Statistical Analysis System version 8.0. SAS Inst, Cary, NC. 
343 Silva, S.C., Nascimento Júnior, D. and Euclides, V.B.P., 2008. Pastagens: conceitos básicos, produção e 344 manejo. Suprema, Viçosa, MG. 
Table 1 - Description of each contemporary group of Nellore beef cattle used in feedlot performance tests.

\begin{tabular}{|c|c|c|c|c|c|c|c|c|c|c|c|c|}
\hline Groups & $\begin{array}{l}\text { Experimental } \\
\text { year }\end{array}$ & $\begin{array}{l}\text { Year } \\
\text { birth }\end{array}$ & of & $\begin{array}{l}\text { Selection } \\
\text { line }^{\mathrm{a}}\end{array}$ & Sex & $\begin{array}{l}\text { Number of } \\
\text { animals }\end{array}$ & $\begin{array}{l}\text { Initial } \\
\text { (days) }^{\mathrm{b}}\end{array}$ & age & $\begin{array}{l}\text { Initial body } \\
\text { weight }(\mathrm{Kg})^{\mathrm{b}}\end{array}$ & $\begin{array}{l}\text { Experimental } \\
\text { period }^{c}\end{array}$ & Test length (days) & $\mathrm{F}: \mathrm{C}^{\mathrm{d}}$ \\
\hline G1 & 2005 & 2004 & & $\mathrm{SNe}$ e $\mathrm{CNe}$ & female & 64 & 301 & & 198 & Jul to Aug & 56 & $50: 50$ \\
\hline $\mathrm{G} 2$ & 2006 & 2005 & & $\mathrm{SNe}$ e $\mathrm{CNe}$ & female & 63 & 308 & & 199 & Sept to Nov & 70 & $55: 45$ \\
\hline G3 & 2007 & 2006 & & $\mathrm{SNe}$ e $\mathrm{CNe}$ & male & 61 & 268 & & 204 & Jul to Sept & 112 & 44.9:55.1 \\
\hline G4 & 2008 & 2007 & & $\mathrm{SNe}$ e $\mathrm{CNe}$ & male & 61 & 254 & & 194 & Sept to Dec & 112 & 44.9:55.1 \\
\hline G5 & 2009 & 2008 & & $\mathrm{TNe}$ & male & 60 & 309 & & 294 & Jul to Oct & 70 & 44.9:55.1 \\
\hline G6 & 2009 & 2008 & & $\mathrm{TNe}$ & female & 64 & 333 & & 247 & Jul to Oct & 84 & 44.9:55.1 \\
\hline G7 & 2010 & 2009 & & $\mathrm{TNe}$ & male & 60 & 264 & & 249 & Jul to Sept & 73 & 44.9:55.1 \\
\hline G8 & 2010 & 2009 & & $\mathrm{TNe}$ & female & 56 & 210 & & 290 & Aug to Oct & 73 & 44.9:55.1 \\
\hline G9 & 2011 & 2010 & & $\mathrm{TNe}$ & female & 54 & 290 & & 216 & Jul to Sept & 84 & 44.9:55.1 \\
\hline G10 & 2011 & 2010 & & $\mathrm{TNe}$ & male & 61 & 261 & & 243 & Aug to Oct & 72 & 44.9:55.1 \\
\hline G11 & 2012 & 2011 & & $\mathrm{TNe}$ & male & 23 & 275 & & 248 & Jul to Sept & 91 & $65: 35$ \\
\hline G12 & 2012 & 2011 & & $\mathrm{TNe}$ & female & 51 & 324 & & 254 & Aug to Oct & 86 & $65: 35$ \\
\hline
\end{tabular}

${ }^{a} \mathrm{CNe}$ - control Nellore beef cattle selection line, $\mathrm{SNe}$ - selection Nellore beef cattle selection line, TNe - traditional Nellore beef cattle selection line

${ }^{\mathrm{b}}$ Average

${ }^{c}$ Jul - July, Aug - August, Sept - September, Oct - October, Nov - November, Dec - December.

${ }^{\mathrm{d}} \mathrm{F}: \mathrm{C}-$ forage to concentrate ratio of the diet 
Table 2 - Ingredients of experimental diets, crude protein content, and total digestible nutrients provided to each group of animals.

\begin{tabular}{|c|c|c|c|c|c|c|c|c|c|c|c|c|}
\hline \multirow{2}{*}{ Ingredient (\%) } & \multicolumn{12}{|c|}{ Groups } \\
\hline & G1 & $\mathrm{G} 2$ & G3 & G4 & G5 & G6 & G7 & G8 & G9 & G10 & G11 & G12 \\
\hline Mixed silage $^{\mathrm{a}}$ & 50.00 & 50.00 & - & - & - & - & - & - & - & - & - & - \\
\hline Whole-plant corn silage & - & - & - & - & - & - & - & - & - & - & 64.23 & 64.23 \\
\hline Brachiaria brizantha hay & - & - & 44.90 & 44.50 & 44.50 & 44.50 & 44.50 & 44.50 & 44.50 & 44.50 & - & - \\
\hline Ground corn grain & 25.60 & 22.70 & 31.90 & 32.20 & 32.20 & 32.20 & 32.20 & 32.20 & 32.20 & 32.20 & 21.89 & 21.89 \\
\hline Soybean meal & - & - & - & - & - & - & - & - & - & - & 11.67 & 11.67 \\
\hline Cotton meal & 22.00 & 19.70 & - & - & - & - & - & - & - & - & - & - \\
\hline Cottonseed meal & - & - & 21.50 & 21.40 & 21.40 & 21.40 & 21.40 & 21.40 & 21.40 & 21.40 & - & - \\
\hline Urea & 0.30 & 0.20 & - & 0.48 & 0.48 & 0.48 & 0.48 & 0.48 & 0.48 & 0.48 & 0.72 & 0.72 \\
\hline Ammonium sulfate & - & - & - & 0.05 & 0.05 & 0.05 & 0.05 & 0.05 & 0.05 & 0.05 & - & - \\
\hline Limestone & 1.03 & 1.00 & - & - & - & - & - & - & - & - & - & - \\
\hline Mineral supplement & 1.12 & 1.40 & 1.70 & 1.40 & 1.40 & 1.40 & 1.40 & 1.40 & 1.40 & 1.40 & 1.45 & 1.45 \\
\hline Crude protein & 14.58 & 14.39 & 10.25 & 11.20 & 13.38 & 13.58 & 14.00 & 14.00 & 11.34 & 11.34 & 13.19 & 13.19 \\
\hline Total digestible nutrients & 58.18 & 60.14 & 60.77 & 69.85 & 61.30 & 61.30 & 60.80 & 60.80 & 62.35 & 62.35 & 66.80 & 66.80 \\
\hline
\end{tabular}

${ }^{a}$ Whole-plant corn intercropped with Panicum maximum. 
Table 3 - Performance and feed intake of Nellore beef cattle according to three different residual intake and gain classes during feedlot performance test.

\begin{tabular}{|c|c|c|c|c|c|}
\hline \multirow[b]{2}{*}{ Measure/Trait ${ }^{\mathrm{a}}$} & \multicolumn{3}{|c|}{ Classes of Residual Intake and Gain ${ }^{\mathrm{b}}$} & \multirow[b]{2}{*}{$\mathrm{SEM}^{\mathrm{c}}$} & \multirow[b]{2}{*}{ P-value } \\
\hline & $\begin{array}{l}\text { Low } \\
(\mathrm{n}=182)\end{array}$ & $\begin{array}{l}\text { Medium } \\
(\mathrm{n}=235)\end{array}$ & $\begin{array}{l}\text { High } \\
(\mathrm{n}=193)\end{array}$ & & \\
\hline Initial weight $(\mathrm{kg})$ & 218.08 & 214.41 & 221.33 & 8.32 & 0.0524 \\
\hline Final weight $(\mathrm{kg})$ & 284.19 & 282.50 & 290.23 & 10.23 & 0.0581 \\
\hline Average body weight $(\mathrm{kg})$ & 251.14 & 248.45 & 255.78 & 9.12 & 0.0552 \\
\hline $\mathrm{BW}^{0.75}(\mathrm{~kg})^{\mathrm{a}}$ & 63.06 & 62.63 & 64.07 & 1.74 & 0.0422 \\
\hline Dry matter intake (kg/day) & $6.71 \mathrm{a}$ & $6.33 \mathrm{~b}$ & $6.11 \mathrm{~b}$ & 0.17 & $<0.0001$ \\
\hline Dry matter intake (\%BW) & $2.69 \mathrm{a}$ & $2.57 \mathrm{~b}$ & $2.41 \mathrm{c}$ & 0.05 & $<0.0001$ \\
\hline Average daily gain (kg/day) & $0.85 \mathrm{~b}$ & $0.88 \mathrm{ab}$ & $0.90 \mathrm{a}$ & 0.04 & $<0.0001$ \\
\hline
\end{tabular}

${ }^{\mathrm{a}} \mathrm{BW}^{0.75}-$ metabolic body weight

${ }^{b}$ Means followed by different letters in lines are statistically different by Tukey test at $1 \%$ level of probability

${ }^{c}$ SEM - standard error of mean 
Table 4 - Feed efficiency traits of Nellore beef cattle according to three different residual intake and gain classes during feedlot performance test.

\begin{tabular}{|c|c|c|c|c|c|}
\hline \multirow[b]{2}{*}{ Trait } & \multicolumn{3}{|c|}{ Classes of Residual Intake and Gain ${ }^{\mathrm{a}}$} & \multirow[b]{2}{*}{$\mathrm{SEM}^{\mathrm{b}}$} & \multirow[b]{2}{*}{$\mathrm{P}$-value } \\
\hline & $\begin{array}{l}\text { Low } \\
(\mathrm{n}=182)\end{array}$ & $\begin{array}{l}\text { Medium } \\
(\mathrm{n}=235)\end{array}$ & $\begin{array}{l}\text { High } \\
(\mathrm{n}=193)\end{array}$ & & \\
\hline Residual feed intake (kg/day) & $0.404 \mathrm{a}$ & $0.001 \mathrm{~b}$ & $-0.383 \mathrm{c}$ & 0.017 & $<0.0001$ \\
\hline Residual gain (kg/day) & $-0.078 \mathrm{c}$ & $0.004 \mathrm{~b}$ & $0.068 \mathrm{a}$ & 0.007 & $<0.0001$ \\
\hline Residual intake and gain & $-0.481 \mathrm{c}$ & $0.003 \mathrm{~b}$ & $0.415 \mathrm{a}$ & 0.018 & $<0.0001$ \\
\hline Kleiber rate (kg/day) & 0.013 & 0.014 & 0.014 & 0.0002 & 0.0100 \\
\hline Relative growth rate (kg/day) & 0.151 & 0.158 & 0.154 & 0.003 & 0.0563 \\
\hline Feed conversion ratio (feed/gain) & $8.18 \mathrm{a}$ & $7.45 \mathrm{~b}$ & $7.01 \mathrm{c}$ & 0.334 & $<0.0001$ \\
\hline Feed efficiency (gain/feed) & $0.13 \mathrm{c}$ & $0.14 \mathrm{~b}$ & $0.15 \mathrm{a}$ & 0.006 & $<0.0001$ \\
\hline
\end{tabular}


Table 5 - Phenotypic correlations between performance and feed efficiency traits in Nellore beef cattle on feedlot performance test.

\begin{tabular}{|c|c|c|c|}
\hline Measure/Trait & $\begin{array}{c}\text { Residual intake and } \\
\text { gain }\end{array}$ & $\begin{array}{l}\text { Residual } \\
\text { gain }\end{array}$ & $\begin{array}{c}\text { Residual feed } \\
\text { intake }\end{array}$ \\
\hline Initial BW (kg) & -0.02 & -0.07 & 0.00 \\
\hline Final BW (kg) & 0.00 & 0.05 & 0.01 \\
\hline $\mathrm{BW}^{0.75}(\mathrm{~kg})^{\mathrm{a}}$ & 0.00 & 0.00 & 0.00 \\
\hline Body weight (kg) & -0.01 & -0.01 & 0.01 \\
\hline Dry matter intake (kg/d) & $-0.27 *$ & 0.00 & $0.31 *$ \\
\hline Average daily gain $(\mathrm{kg} / \mathrm{d})$ & 0.09 & $0.42 *$ & 0.00 \\
\hline $\begin{array}{l}\text { Dry matter intake/body weight } \\
(\% \mathrm{BW})\end{array}$ & $-0.42 *$ & 0.02 & $0.50 *$ \\
\hline Residual feed intake (kg/day) & $-0.98 *$ & $-0.56^{*}$ & --- \\
\hline Residual gain (kg/day) & $0.70 *$ & --- & $-0.56 *$ \\
\hline Residual intake and gain & --- & $0.70 *$ & $-0.98 *$ \\
\hline Kleiber ratio (kg/day) & 0.09 & $0.42 *$ & 0.00 \\
\hline Relative growth rate (kg/day) & 0.05 & $0.36 *$ & 0.03 \\
\hline Feed conversion ratio (feed/gain) & $-0.31 *$ & $-0.50 *$ & $0.23 *$ \\
\hline Feed efficiency (gain/feed) & $0.34 *$ & $0.51 *$ & $-0.26^{*}$ \\
\hline
\end{tabular}

${ }^{\mathrm{a}} \mathrm{BW}^{0.75}$ - metabolic body weight

* Correlations are different from zero at $\mathrm{P}<0.01$. 